\title{
RELATIONAL MECHANISMS IN INNOVATION CO-CREATION
}

\author{
Rodica Boier \\ “Gheorghe Asachi” Technical University of Iaşi \\ Rodica_Boier@yahoo.com
}

\begin{abstract}
Increasingly, producers and customers establish relationships to mutually undertake the development of an innovative product. Consequently, it will be always of interest for an innovative company to know the degree to which different related suppliers are willing to form partnerships by participating in its new product development process. Several managerial implications flow from the link between relationship marketing and innovation processes, ranging from tactical product-related decisions to strategic competitor-related decisions, usually made in a relatively short period of time. Dedicated customer relationship systems track the interactions with customers and improve the flow of ideas for new products. When trying to develop long-term customer relationships, the ability to provide superior value to stakeholders is a must. Through carefully conducted relationships, customers are linked with the innovation company during the entire innovation process, and create a space for mutual understanding, learning and value co-creation. In order to co-create business value through online, also combined with offline innovation-related activities, customer orientation should be implemented throughout the organization - its culture, their systems, including the whole range of interactions.
\end{abstract}

\section{Keywords}

relationship marketing; innovation co-creation; value co-creation; open innovation; virtual customer environments; knowledge exchange platform.

\section{JEL Classification}

M31

\section{Relational mechanisms in innovation}

At their very basic level, antecedents of the relationship marketing lie in the product aspects, market variables and characteristics of relationship activities. The resulting commitment to stay in the relationship comes from trust, which is in turn positively related to affective commitment, on the one hand, and negatively related to calculative commitment, on the other hand (De Ruyter et al., 2001). Several managerial implications flow from these findings, ranging from tactical productrelated decisions to strategic competitor-related decisions, usually made in a relatively short period of time. For instance, marketers of high technology products are especially advised to emphasize activities and initiatives that promote positive feelings of affiliation and create a cooperative atmosphere. Long-term relationships with customers can provide all kinds of advantages for suppliers. In return, there is a constant pressure for the company on R\&D departments to, for example, develop new and innovative products, facilities, or flexible service contracts.

Increasingly, seller and a buyer establish relationships to mutually undertake the development of an innovative product. The NPD relationships generate the „cooperative competency” (Sivadas and Dwyer, 2000) and involve the product codesign, product co-development, joint problem solving a.s.o. As part of this context, a 
major part of relationship marketing deals with the interactions between sellers and buyers during the NPD process when customizing the products.

According to Athaide at al. (2003), „... the extent to which sellers undertake NP codevelopment relationships is a function of perceived buyer knowledge and the extent of prior interactions with the buyer as well as the degree of product customization involved" (p. 46). In addition, Stump at al. (2002) investigated how various relationship activities conducted by the producer during the NPD process - education, product knowledge generation, and joint NPD - moderate product customization effect on qualitative outcomes. For instance, their findings show that joint NPD reduces the negative effect of product customization on seller satisfaction and enhances customization's positive effect on continuity.

It will be always of interest for an innovative company to know the degree to which different related suppliers are willing to form partnerships by participating in its NPD process. In this respect, LaBahn and Krapfel (2000, p. 181-182) found the customer's exchange behavior, the structure of dependence in a relationship, and the technology factors as being the three key areas of positive influences on supplier intention for early supplier involvement.

\section{Value co-creation and relationship marketing}

When trying to develop long-term customer relationships, the ability to provide superior value to stakeholders, to customers first, is a must. In a comprehensive study, Blocker et al. (2011) found that proactive customer orientation not only has a positive effect on loyalty through the value-satisfaction-loyalty chain but it may also reveal a positive effect on loyalty (p. 229).

Still emerging paradigm, flowing from marketing and innovation areas, the value cocreation is increasingly recognized as an effective opportunity for NPD. No more just simple informants, the stakeholders become an integrated part of the NPD process. Through carefully conducted relationships, they are linked with the innovation company during the entire NPD process, and create a space for mutual understanding, learning and value co-creation. There is to be mentioned, the focus of co-creation is on personalization and not on customization (Tanev, 2009).

A growing body of studies were dedicated to this aspect of the contemporary business in innovation, ranging from a virtual customer environments perspective (Füller, 2010; Nambisan and Baron, 2007, 2009; Nambisan and Nambisan, 2008), to a NPDI approach (Franke et al., 2008; Prahalad and Krishnan, 2008; Sawhney et al., 2006 a.o.), the service-dominant logic perspective (Brohman et al., 2009; Ballantyne and Varey, 2006; Vargo and Lusch, 2004), to a general management view (Ramaswamy and Goullart, 2010; Ramaswamy, 2009; Jaworski and Kohli, 2006; Prahalad and Ramaswamy, 2000, 2004; Nambisan and Nambisan, 2008 a.o.).

As opposed to the customer-focused innovation, where innovation is done by the company (closed innovation), or to the customer-centered innovation, where innovation is done with customers (open innovation), in the customer-driven innovation these activities are done by customers (dynamic innovation), as a central entity and key-player, where the innovative company has only a role of coordinator and the innovation process is quite impossible to control. "Sticky" and tacit knowledge transfer require high levels of human interaction and the appropriate segmentation for proper analysis represent the critical issues here (Desouza et al., 2008).

Dedicated CRM systems track the interactions with customers and improve the flow of ideas for NPs. Described as an ongoing process of generating, disseminating and using customer knowledge within a company and between the company and its customer, Customer Knowledge Management (CKM) may exists in four forms, each 
of them using knowledge in different ways: knowledge of customers, knowledge for customers, knowledge from customers, and knowledge co-creation. The last one is obtained from a real two-way relationship, conducted to facilitate ongoing interactions between customers and companies to obtain new knowledge, new products and services. This way, the KM integration to the CRM and marketing reduces the risk of NP failing on the market (Talet, 2012; Sofianti et al., 2010).

Grönroos and Ojasalo (2004) propose a "knowledge exchange platform", as fertile area for ongoing interactions. Relationship continuity is sustained to lead to improved internal efficiency and offers more effectively aligned to the customer needs. In such relationships, there is no dominant researcher. All decisions about the research topic, the research method, and the writing are considered jointly (Jaworski and Kohli, 2006).

The framework described by Prahalad and Ramaswamy in the Co-creating unique value with customers contains four elements as basic building blocks of value cocreation - dialogue, access, risk assessment, and transparency (DART) (2004, p. 6-7) -, all of them containing innovation-specific relationships. In addition, Tanev at al. (2011) propose "Customer relationships enabled through partnerships and cooperation aiming at cost reduction, design and process flexibility, and leading to better customer and end user experiences based on risk management, transparency and trust” as being one of the three variable describing main value co-creation components, along with "Resources, processes, tools and mechanisms ..." and "Mutual learning mechanisms ...” (p. 5).

The very nature of relationships between the innovative company and its co-creators of value, the different stakeholders, changes by adopting these practices. A growing number of studies evoque the new vision of the nature of innovation itself (Prahalad şi Krishnan, 2008; Tanev et al., 2011), built on two key distinctive aspects: the deepest user-driven practice of the value co-creation between companies and customers, on the one hand, and the co-opetitive nature of interactions between different stakeholders during the NPD process, on the other hand.

\section{Marketing relationship in collaborative innovation}

Collaborative innovation is considered as interorganizational relationships (different suppliers, customers, even competitors, for selected projects) focused on the joint development of innovations (Stuart, 2000; Ahuja, 2000), in which the specific approach involves combining knowledge, technologies, and other resources across organizational boundaries, with specific outcomes like intellectual property, commercial products and platforms, market success and company performance. At least three main mechanisms sustain successful collaborative innovation: the engagement of different participants from the network, having different knowledge and other resource inputs, the combination of complementary capabilities from both partners, the deep and broad trajectory searching for potential innovations, as series of „recombinations” between existing resources (Katila and Ahuja, 2002).

In opposition to dominating and consensus leadership processes, usually associated with less innovation, Davis and Eisenhardt (2011) propose a rotating leadership process that involve alternating the control of decision making across phases, zigzagging objectives that engender deep and broad technological search for potential innovations, and fluctuating network cascades that mobilize different participants who bring variable inputs to recombination (p. 191). This way, the long lived relationships, often becoming inertial and less beneficial, can be turned to a so-called symbiotic relationships, which continue to be adaptive for long periods of time.

In a networking perspective of the collaborative innovation, companies are forced to develop their skills for collaborating with diverse partners, to play a championing 
role, rather than seeking to control the activities in the collaboration platform. It means to subsume their individual agendas to the larger goals of the platform, to adapt some of their existing practices, to get more specialized and more flexible (more modular), and to measure success in ways that appeal to all partners (Nambisan and Baron, 2009, p. 48). How to identify, to select and foster such a champion in the collaborative innovation remain the important challenges.

Over the last years there has been a rapidly growing interest in innovation co-creation (ICC), even mentioned in the literature as being a truly „co-creation revolution” (Humphreys et al., 2009). Relationships developed prior, during and after the ICC process have several main benefits, the most important being the capture of new ideas, an important percent of the solution being already built, the instant channel to distribute the novel idea this way, the pull-type of the process instead of push, the ICC partners moving together through the innovation process, so they will both support what they created (Maddock and Viton, 2010), the improvement of costs efficiency (Auh et al., 2007), the decrease of cycle time (Matthing et al., 2004) and the increase of customer satisfaction.

New ICT have reduced the perceived distances between the actors of the innovation process while enabling integration of different stakeholders, customers and suppliers first, into the NPD process (Gassmann, 2006). A growing literature on community based innovation (Füller et al., 2004, 2006) and using lead-users from virtual communities was stimulated by companies' efforts to establish and maintain an innovative relationship and collaboration with customers already in the early phases of the NPD process (Franz and Wolkinger, 2003; Nambisan and Baron, 2007; Nambisan and Nambisan, 2008; Sawhney et al., 2005; Jeppesen and Molin, 2003).

An integrated model of involving lead users in the early stages of the NPD links the "Enabling Factors" with the "Management Phase" and the "Relational Phase" having the project manager at its center, to reach the specific "NPD Outcomes" (Lynch and Holden, 2008, p. 5). About enablers, as prerequisites, along with the internal and external ones, the model also contains the relational enablers - compatibility of culture, past experience of collaborating, and ability to handle conflicts. Among others, in the Relational Phase, the roles of project champion are to handle expectations, to ensure appreciation of other's identity, to establish effective communication patterns, to build inter-organisational trust through inter-personal relationships, to encourage intense levels of interaction, and to audit the relationship.

A growing number of innovative companies are hosting virtual customer environments (VCEs) to allow the involvement of their customers in the NPD support activities. Classified according to their characteristics of community members and interaction level as virtual customer community, beta testing volunteer corps, user content collaboration innovation community, user development community and user product collaboration innovation community (Chan and Lee, 2004), the VCEs can be used in different stage of the NPD process, including in the intermediate stages of design and engineering, where these activities are often weaker.

In the open source software (OSS), where companies explicitly try to utilize the resources within communities in order to create and appropriate value, with just a partial and not direct control, the relationships can be very different. In this context, Dahlander and Magnusson (2005) describe three different basic approaches used by companies to inter-relate to their communities as a symbiotic (the company tries to codevelop itself and the community), a commensalistic (the company benefits from the co-existence with the community while leaving it without harm) or a parasitic (the company only focuses on its own benefits, without taking into account that its actions might harm the community) approach (p. 487-488). The first approach described offers the most possibilities for the company to influence the community in order to participate in the innovation process. 


\section{Conclusions}

A growing body of studies were dedicated to this emerging aspect of the contemporary business in innovation - the realtionship approach. Mechanisms of creating value in co-innovation and marketing relationships in collaborative and/or participative innovation raise more and more interest in the literature and practice of the domain.

In order to co-create business value through online, also combined with offline innovation-related activities, customer orientation should be implemented throughout the organization - its culture, their systems, including the whole range of interactions.

\section{References}

Ahuja, G. (2000), Collaboration networks, structural holes, and innovation: A longitudinal study, Administrative Science Quarterly, vol. 45, no. 3, pp. 425455.

Athaide, G.A., Stump, R.L., Joshi, A.W. (2003), Understanding new product codevelopment relationships in technology-based, industrial markets, Journal of Marketing Theory and Practice, vol. 11, no. 3, pp. 46-58.

Auh, S., Bell, S., McLeod, C., Shih, E. (2007), Co-production and customer loyalty in financial services, Journal of Retailing, vol.83, pp.359-370.

Ballantyne, D., Varey, R. J. (2006), Creating value-in-use through marketing interaction: the exchange logic of relating, communicating and knowing, Marketing Theory, vol. 6, no. 3, pp. 335-348.

Blocker, C.P., Flint, D., Myers, M.B., Slater, S.F. (2010), Proactive Customer Orientation and Its Role for Creating Customer Value in Global Markets, Journal of The Academy of Marketing Science, no. 39, pp. 216-233.

Brohman, M.K., Piccoli, G., Martin, P., Zulkernine F.H., Parasuraman, A., Watson, R.T. (2009), A design theory approach to bulding strategic network-based customer service systems, Decision Sciences, vol. 40, no. 3, pp. 403-430.

Chan, T.-Y., Lee, J.F. (2004), A Comparative study of online user communities involvement in product innovation and development, Proceedings of the 13th International Conference on Management of Technology (IAMOT), Washington D.C.

Dahlander, L., Magnusson, M. (2005), Relationships between open source software companies and communities: Observations from Nordic firms, Research Policy, vol. 34, no. 4, pp. 481-493.

Davis, J.P., Eisenhardt, K.M. (2011), Rotating Leadership and Collaborative Innovation: Recombination Processes in Symbiotic Relationships, Administrative Science Quarterly, vol. 56, no. 2, pp. 159-201.

de Ruyter, K., Moorman, L., Lemmink, J. (2001), Antecedents of commitment and trust in customer-supplier relationships in high technology markets, Industrial Marketing Management, vol. 30, no. 3, pp. 271-286.

Desouza, K C., Awazu, Y., Jha, S., Dombrowski, C., Papagari, S., Baloh, P., Kim, J.Y. (2008), Customer-driven innovation, Research-Technology Management, vol. 51, no. 3, p. 35-44.

Franke, N., Keinz, P., Schreier, M. (2008), Complementing Mass Customization Toolkits with User Communities: How Peer Input Improves Customer SelfDesign, Journal of Product Innovation Management, vol. 25, no. 6, pp. 546559.

Franz, R., Wolkinger, T. (2003), Customer integration with virtual communities. Case study: The online community of the largest regional newspaper in Austria, Proceedings of the Hawaii International Conference on System Sciences (HICSS), January 6-9, Big Island, Hawaii, pp. 214-222. 
Füller, J. (2010), Refining virtual co-creation from a consumer perspective, California Management Review, vol. 52, no. 2, pp. 98-122.

Füller, J., Bartl, M., Ernst, H., Mühlbacher, H. (2006), Community Based Innovation: How to Integrate Members of Virtual Communities into New Product Development, Electronic Commerce Research, vol. 6, no. 1, pp. 57-73.

Füller, J., Bartl, M., Ernst, H., Mühlbacher, H. (2004), Community Based Innovation - A Method to Utilize the Innovative Potential of Online Communities, Proceedings of the 37th Hawaii International Conference on System Sciences, Los Alamitos, IEEE Press, pp. 195-204.

Gassmann, O. (2006), Opening up the innovation process: towards an agenda. Editorial, R\&D Management, vol 36, no. 3, pp. 223-228.

Grönroos, C., Ojasalo, K. (2004), Service productivity: Towards a conceptualization of the transformation of inputs into economic results in services, Journal of Business Research, vol. 57, no. 4, pp. 414-423.

Humphreys, P., Samson, A., Roser, T., Cruz-Valdivieso, E. (2009), Co-creation: New pathways to value. An overview, Promise/LSE Enterprise, London.

Jaworski, B.J., Kohli, A. K. (2006), Co-Creating the Voice of the Customer, in Lusch, R.F., Vargo, S. (edit.), The service-dominant logic of marketing: dialog, debate, and directions, M.E. Sharpe, New York, pp. 109-117.

Jeppesen, L.B., Molin, M.J. (2003), Consumers as Co-developers: Learning and Innovation Outside the Firm, Technology Analysis \& Strategic Management, vol. 15, no. 3, pp. 363-383.

Katila, R., Ahuja, G. (2002), Something old, something new: a longitudinal study of search behavior in new product introduction, Academy of Management Journal, vol. 45, no. 6, pp. 1183-1194.

LaBahn, D.W., Krapfel, R. (2000), Early Supplier Involvement in Customer New Product Development: A Contingency Model of Component Supplier Intentions, Journal of Business Research, no. 47, pp. 173-190.

Lynch, P., Holden, M.T. (2008), Users as co-inventors: a model of involving users in the early stages of new product development, Proceedings of the Irish Academy of Management (IAM) Conference, September 3-5, Dublin, Ireland.

Maddock, G.M., Viton, R.L. (2010), Why Victims Can't Invent Anything, Businessweek, January 05.

Matthing, J., Sande'n, B., Edvardsson, B. (2004), New service development: learning from and with customers, International Journal of Service Industry Management, vol. 15 no. 5, pp. 479-98.

Nambisan, S., Baron, S. (2009), Virtual customer environments: Testing a model of voluntary participation in value co-creation activities, Journal of Product Innovation Management, no. 26, pp. 388-406.

Nambisan, S., Nambisan, P. (2008), How to profit from a better virtual customer environment, MIT Sloan Management Review, vol. 49, no. 3, pp. 53-61.

Nambisan, S., Baron, R. (2007), Interactions in virtual customer environments: Implications for product support and customer relationship management, Journal of Interactive Marketing, vol. 21, no. 2, pp. 42-62.

Prahalad, C.K., Krishnan, M.S. (2008), The new age of innovation: driving cocreated value through global networks, McGraw-Hill, New York, NY.

Prahalad, C.K., Ramaswamy, V. (2004), The future of competition: Co-creating unique value with customers, Harvard Business Review Press, Boston, MA.

Prahalad, C.K., Ramaswamy, V. (2000), Co-opting Customer Competence, Harvard Business Review, vol. 78, no. 1, pp. 79-87.

Ramaswamy, V., Goullart, F. (2010), The Power of Co-Creation: Build It with Theam to Boost Growth, Productivity, and Profits, Free Press, New York, NY. 
Ramaswamy, V. (2009), Leading the transformation to co-creation of value, Strategy \& Leadership, vol. 37, no. 2, pp. 32-37.

Sawhney, M., Wolcott, R.C., Arroniz, I. (2006), The 12 different ways for companies to innovate, MIT Sloan Management Review, no. 47, pp. 75-81.

Sawhney M., Verona G., Prandelli E. (2005), Collaboration to Create: the Internet as a Platform for Customer Engagement in Product Innovation, Journal of Interactive Marketing, vol. 19, no. 4, pp. 4-17.

Sivadas, E., Dwyer, F.R. (2000), An examination of organizational factors influencing new product success in internal and alliance-based processes, Journal of Marketing, vol. 64, no. 1, pp. 31-49.

Sofianti, T.D., Suryadi, K., Govindaraju, R., Prihartono, B. (2010), Customer Knowledge Co-creation Process in New Product Development, Proceedings of the World Congress on Engineering, vol. I, London, U.K.

Stuart, T.E. (2000), Interorganizational alliances and the performance of firms: a study of growth and innovation rates in a high-technology industry, Strategic Management Journal, vol. 21, no. 8, pp. 791-811.

Stump, R.L., Athaide, G.A., Joshi, A.W. (2002), Managing seller-buyer new product development relationships for customized products: a contingency model based on transaction cost analysis and empirical test, Journal of Product Innovation Management, vol. 19, no. 6, pp. 439-454.

Talet, A.N. (2012), KM Process and CRM to manage Customer Knowledge Relationship Management, Proceedings of the International Conference on Economics, Business and Marketing Management IPEDR, vol. 29, IACSIT Press, Singapore.

Tanev, S., Ruskov, P., Georgiev, L., Bailetti, T. (2011), A Business Intelligence Tool for Studying Value Co-creation and Innovation, Information technologies and control, no. 1, pp. 2-9.

Tanev, S., Knudsen, M., Gerstlberger W. (2009), Value co-creation as part of an integrative vision for innovation management, Timreview, Open source business review online journal [http://timreview.ca/article/309, accessed 07 May 2014].

Vargo, S.L., Lusch, R.F. (2004), Service-Dominant Logic: Continuing the Evolution, Journal of the Academy of Marketing Science, vol. 36, no. 1, pp. 1-10. 